\title{
Evaluation of Wear and Corrosion Properties of AA6061/TiB 2 Composites Produced by FSP Technique
}

\author{
Dakarapu Santha Rao1, Nallu Ramanaiah² \\ ${ }^{1}$ Department of Mechanical Engineering, BVC Engineering College, Odalarevu, India \\ ${ }^{2}$ Department of Mechanical Engineering, A.U. College of Engineering (A), Vishakhapatnam, India \\ Email: dsantharao@gmail.com,n.rchetty1@gmail.com
}

How to cite this paper: Rao, D.S. and Ramanaiah, N. (2017) Evaluation of Wear and Corrosion Properties of $\mathrm{AA}_{6061 / \mathrm{TiB}_{2}}$ Composites Produced by FSP Technique. Journal of Minerals and Materials Characterization and Engineering, 5, 353-361. https://doi.org/10.4236/jmmce.2017.56029

Received: April 23, 2017

Accepted: October 16, 2017

Published: October 19, 2017

Copyright (๑) 2017 by authors and Scientific Research Publishing Inc. This work is licensed under the Creative Commons Attribution International License (CC BY 4.0).

http://creativecommons.org/licenses/by/4.0/

\begin{abstract}
Aluminum alloys are used frequently in aerospace and ship building industry. Due to poor wear and corrosion resistance, conventional aluminum alloys are replaced by metal matrix composites (MMC). Aluminum alloy matrix reinforced with ceramic particles $\left(\mathrm{TiB}_{2}\right)$ has importance in industry where components slide each other. The main task is to produce MMCs with low cost effective way to meet the requirement. In this study, an attempt is made to produce $\mathrm{AA} 6061 / \mathrm{TiB}_{2}$ MMCs with different volume fractions of ceramic particles using friction stir processing technique. The dry sliding wear behavior of composites was investigated using pin on disc method. The lowest wear resistance has obtained for $8 \%$ composite. The corrosion of composites was analyzed by salt spray method. It was found that wear and corrosion resistance was increased with increase of reinforcement which was higher for $8 \%$ composite.
\end{abstract}

\section{Keywords}

Friction Stir Processing, $\mathrm{TiB}_{2}$, Metal Matrix Composites, Wear, Corrosion

\section{Introduction}

Aluminum Alloys are widely used in industrial applications automotive, aerospace and ship building area due to high strength to weight ratio and better corrosion resistance but they exhibit inferior tribological properties [1]. Aluminum metal matrix composites (AMCs) are widely replacing conventional aluminum alloys in many applications due to superior mechanical properties and tribological properties [2] [3]. The composites are made of two constituent phases. One 
phase is called reinforcement phase and other one is called as matrix phase. These two phases are not soluble but macroscopically combined the constituents. A lot of research has been carried out to enhance the properties of AMCs using various methods and different reinforcements like $\mathrm{Al}_{2} \mathrm{O}_{3}, \mathrm{~B}_{4} \mathrm{C}$ TiC, CNT, $\mathrm{SiO}_{2}$, Fly Ash, $\mathrm{TiO}_{2}$, Graphite, SiCetc [4] [5]. The Aluminum metal matrix composites are produced by liquid metallurgy route such as conventional stir casting and electromagnetic stir casting [5] [6], Squeeze casting [7], Pressure Infiltration [8]. The literature on reinforcement titanium diboride $\left(\mathrm{TiB}_{2}\right)$ is less and can be much interest due to excellent strength, hardness, and wear and corrosion resistance.

It is difficult to mix the reinforcement to liquid aluminum due to the poor wettability of both matrix and reinforcement [9]. The reinforcement particles may tend to react and forms compounds which degrade the properties of composites. The liquid metallurgy routes are most economical for mass production; the homogeneous distribution of reinforcement particles in the casting is challenge task [10]. The powder metallurgy method is high expensive, time and energy consuming and it is difficult to obtain a bulk material with high density [11]. The process parameters influence the solidification structure of AMCs that demands precise control.

The Friction stir processing (FSP) is modification of FSW [12] techniques which refines the microstructure, improves the mechanical properties and also be used for production of composite in solid state itself. Further this process produces a homogeneous distribution of reinforcement particles in the aluminum matrix [13]. This process is environmentally clean technology as it does not produce any fumes and harmful gases and noise like in other conventional techniques. The temperatures developed during the FSP was below the melting point of material which avoids interfacial reactions, defects like pin hole porosity, air inclusions be eliminated.

Recently, FSP was emerged as novel technique to fabricate metal composites and is based on the FSW. In this process, the aluminum alloys metal matrix composites in the solid state itself. At first, the groove or small holes are made in the plates and reinforcement particles are packed in it (Figure 1(a)). Then particles are filled in the groove (Figure 1(b)) and compacted with pin less tool (Figure $1(\mathrm{c})$ ). Finally tool pin was plunged at one end of plate and transverse across the plate (Figure 1(d)). The shoulder touches the surface of plate and produces frictional heat which plasticized the material. The tool pin stirs and mixes the matrix material with reinforcement and produces the composites shown in the Figure 1.

A. Thangarasu et al. [13] has produced the AA6081/TiC composite using FSP with different volume proportions of reinforcement and has found that UTS and Hardness were increased and observed more uniform distribution of particles. S. R. Anvari et al. [14] investigated wear properties of AA6061/Al-Cr-O hybrid nano composites produced by FSP and showed improved wear resistance of 


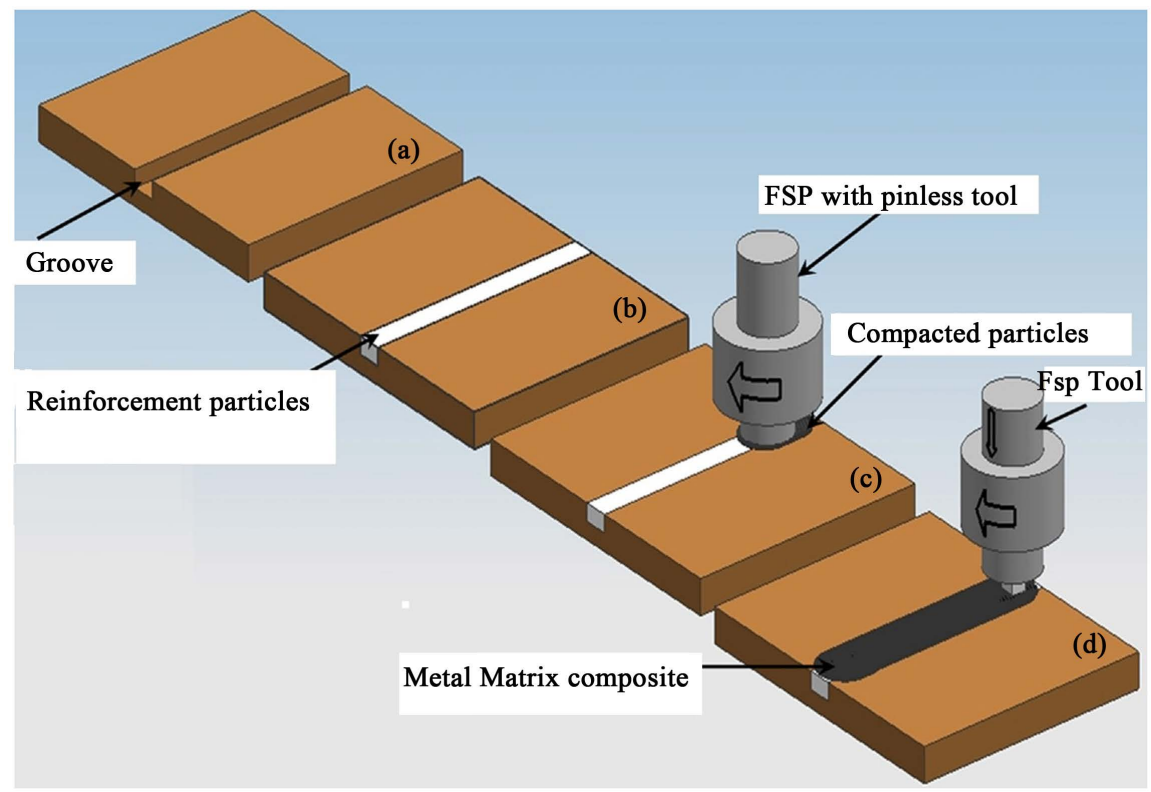

Figure 1. Basic FSP process.

composite sample due to homogeneous dispersion of ceramic particles. Tyagi et al. [15] studied the wear behavior of AL-TiC composites by melt reaction method and showed that wear rate was lower when compared to pure aluminum and linearly decreases wear rate with increase of volume fraction of titanium carbide which was due to presence of hard particles. S. Gopalakrishna et al. [16] fabricated AA 6061/TiC composites using stir casting method and reported that wear rate has reduced by $40 \%$ by increasing the volume fraction of from $3 \%$ to 7\%. B. Ashok Kumar et al. [17] fabricated AA 6061-AINp composites using stir casting with different mass fraction of $0 \%, 5 \%, 15 \%, 20 \%$. The wear test was carryout by taking the four process parameters and four levels with sliding load, sliding distance, normal load and mass fraction. The found that wear rate was decreased with increase of mass fraction of composite and linearly with increase of other parameters. The adhesive wear was more predominant for base materials and abrasive wear (delamination, cracks) was dominant for composites. I. Dinaharan et al. [18] fabricated and investigated the dry sliding wear of AA $6061 / \mathrm{ZrB}_{2}$ composites by in situ method using reaction salts. They investigated the wear rate by considering the four wear parameters and four levels. The wear rate was reduced with increase of $\mathrm{ZrB}_{2}$ content. The base metal wear surface has deep grooves, large pits and cracks due heat which softens the surface whereas for composites shallow grooves and lesser pits were obtained due to presence of particles. It was observed that increasing wear parameters decreased the wear resistance of composites. Serjul Haque et al. [19] fabricated the AA 6061/SiC MMC composites using stir casting method. They investigated wear properties of composites and found wear rates were less with increasing the stirring speed during fabrication of composite. A. Mandal et al. [20] studied dry sliding behavior of $\mathrm{TiB}_{2}$ composites produced by in situ method. They reported that wear resistance was improved with increase of $\mathrm{TiB}_{2}$. The load bearing capacity of alloy 
increased with presence of $\mathrm{TiB}_{2}$ particles. The SEM analysis suggests that improvement of wear resistance due to formation of finer debris.

From the literature review, it was revealed that wear tests have been conducted extensively for different composites made by different processing methods and not reported $\mathrm{AA} 6061 / \mathrm{TiB}_{2}$ composites by FSP route. Hence an attempt was made to study the wear and corrosion properties of the AA $6061 / \mathrm{TiB}_{2}$ composite made by FSP route.

\section{Experimentation}

The commercially available Aluminum Alloy plates of $6 \mathrm{~mm}$ thick and plates are cut to size of $150 \mathrm{~mm} \times 100 \mathrm{~mm}$. The selected reinforcement is titanium di boride $\left(\mathrm{TiB}_{2}\right)$ powder particles of 99.00 purity and average particle size of $2.0 \mu \mathrm{m}$. The chemical composition and mechanical properties of base metal is presented in the Table 1 and Table 2. The square grooves of $0.5 \mathrm{~mm} \times 3 \mathrm{~mm}, 0.5 \mathrm{~mm} \times$ $5.3 \mathrm{~mm}, 1 \mathrm{~mm} \times 4 \mathrm{~mm}$ in size were made on the center of plate by Wire cut EDM process to accommodate the volume of reinforcement of $0 \%$ (sample 1), $4 \%$ (sample 2), $8 \%$ (sample 3), and $12 \%$ (sample 4), The tool is made of HSS and dimensions of the tool pin were diameter of $6 \mathrm{~mm}$ and $5.5 \mathrm{~mm}$ length and threaded pin of $1 \mathrm{~mm}$ pitch. The rotational speed of $1400 \mathrm{rpm}$ and transverse feed of $20 \mathrm{~m} / \mathrm{min}, 40 \mathrm{~m} / \mathrm{min}, 60 \mathrm{~m} / \mathrm{min}, 80 \mathrm{~m} / \mathrm{min}$ was selected. The powder was packed in the groove after clamping the plate on the machine vice. The tool without pin (first tool) was traversed along the groove to compact the particles and to avoid spattering of powder during FSP. The FSP was carried out indigenously developed FSW machine with threaded pin (second tool) tool tilt angle of $2^{\circ}$ was used for all experiments and single pass FSP was used to fabricate the aluminum metal composites (AMCs). The working arrangement of FSP process and composite after experimentation are shown in Figure 2(a) and Figure 2(b).

Table 1. Chemical composition of AA 6061-T6 alloy.

\begin{tabular}{ccccccccc}
\hline Element & $\mathrm{Mg}$ & $\mathrm{Si}$ & $\mathrm{Fe}$ & $\mathrm{Mn}$ & $\mathrm{Cu}$ & $\mathrm{Cr}$ & $\mathrm{Ti}$ & $\mathrm{Al}$ \\
\hline $\mathrm{Wt} \%$ & 0.825 & 0.711 & 0.342 & 0.023 & 0.152 & 0.017 & 0.083 & balance \\
\hline
\end{tabular}

Table 2. Effect of wear loss, wear rate and coefficient of friction on percentage of reinforcement

\begin{tabular}{ccccc}
\hline Name of sample & $\begin{array}{c}\text { Wear loss } \\
(\text { micro meters })\end{array}$ & $\begin{array}{c}\text { Wear rate } \\
\left(\mathrm{mm}^{3} / \mathrm{m}\right)\end{array}$ & $\begin{array}{c}\text { Coefficient } \\
\text { of friction }\end{array}$ & $\begin{array}{c}\text { Specific wear rate } \\
\left(\mathrm{mm}^{3} / \mathrm{N} \cdot \mathrm{m}\right)\end{array}$ \\
\hline Base Metal & 81.0 & 2.2923 & 0.325 & 0.4073 \\
$\mathrm{AA} 6061-0 \% \mathrm{TiB}_{2} \mathrm{MMC}$ & 68.0 & 3.4 & 0.317 & 0.3400 \\
$\mathrm{AA} 6061-4 \% \mathrm{TiB}_{2} \mathrm{MMC}$ & 14.5 & 0.7291 & 0.121 & 0.07291 \\
$\mathrm{AA} 6061-8 \% \mathrm{TiB}_{2} \mathrm{MMC}$ & 12.5 & 0.563 & 0.191 & 0.06285 \\
$\mathrm{AA} 6061-12 \% \mathrm{TiB}_{2} \mathrm{MMC}$ & 56.3 & 1.598 & 0.210 & 0.2840 \\
\hline
\end{tabular}




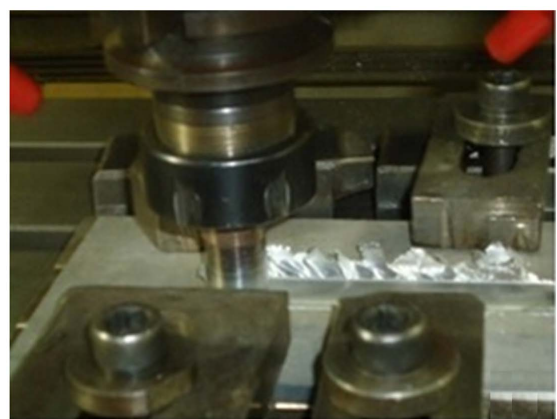

(a)

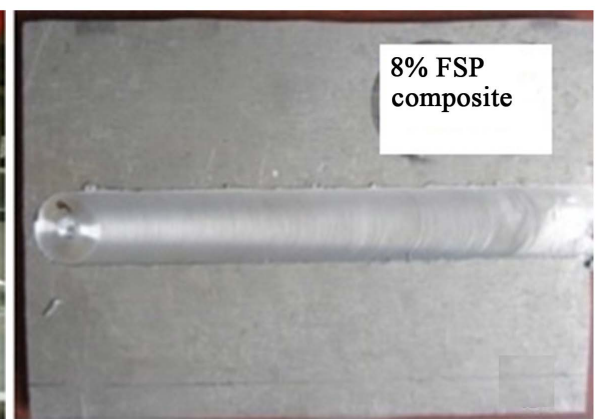

(b)

Figure 2. (a) FSP process; (b) composite.

\subsection{Wear Test}

The dry sliding wear rate was measured on Pin-on-disc test apparatus to investigate the characteristics of composites. The samples were prepared as per ASTM: G99-5 standards and specimens of $6 \mathrm{~mm}$ in diameter were cut in the stir zone normal to the FSP direction and about $30 \mathrm{~mm}$ length (additional length of $24 \mathrm{~mm}$ of length of another material welded to the sample to act as holder). The specimens were polished by emery paper of different grade of 220,320,400, 600, 800. The steel disc made of EN 31 (Hardness of 65 HRC) of diameter selected in the experimentation. A computer aided data acquisition system was used to monitor the loss of height. The wear tests were performed at room temperature of $30^{\circ} \mathrm{C}$ under dry sliding conditions with constant load of $10 \mathrm{~N}$, rotational speed of $(1200 \mathrm{rpm})$ and sliding speed $(10 \mathrm{~N})$ and sliding distance $(2 \mathrm{~m} / \mathrm{s})$. The volumetric loss was computed by multiplying the cross section of the test pin with its loss of height [18]. The wear loss recorded shown in Table 2. After each test the disc was cleaned. The volume loss is calculated by multify the area of pin with wear loss. The wear rates in terms of volume loss per unit sliding distance and per unit normal load were calculated by using the following formula. The worn surfaces of selected specimens were observed using scanning electron microscope.

$$
\text { wear rate }=\frac{\text { volume loss }\left(\mathrm{mm}^{3}\right)}{\text { sliding distance }(\mathrm{m})}
$$

\subsection{Corrosion Test}

The salt spray corrosion tests were carried out in $3.5 \mathrm{wt} \% \mathrm{NaCl}(\mathrm{PH} 7.0)$ solutions for 24 hours to find out the corrosion resistance as per ASTM B 117 standards. The specimens for test was cut stir area perpendicular to stirring direction of size $10 \mathrm{~mm} \times 10 \mathrm{~mm} \times 6 \mathrm{~mm}$ and masked on all sides except to surface. The samples are polished with emery paper and degreased with acetone and rinsed with distilled water before immersion of the specimens. The weight of samples was measured before and after the corrosion test. The weight loss of material was the measure of corrosion rate. The samples were cleaned ultrasonically to remove the salts sticking to the surface for examination of surface with scanning 
electron microscope. The corrosion rate in miles per year was estimated by the following Equations (2) and (3).

$$
\begin{gathered}
\text { Corrosion rate }(\text { mm per year })=\frac{87.6 \times \text { weight loss }}{\text { Area } \times \text { Density } \times \text { time }} \\
\text { Corrosion rate }(\text { miles per year })=\text { corrosion rate per year } \times 472
\end{gathered}
$$

\section{Results and Discussions}

The SEM analysis of worn surfaces of the base metal and composites is shown in Figure 3. The worn surfaces of the base metal have delamination (deep grooves), substantial number of pits and craters. The frictional heat may be caused for plastic deformation which softens the surface and more loss of material [21]. The base metal dominated adhesive wear is shown in the Figure 3(a). The wear pattern of composites has shallow grooves and less pits on the surface is shown in Figures 3(b)-(d). The wear mechanism in composites may be due to ploughing, and preceded by a digging out of the $\mathrm{TiB}_{2}$ particles from the aluminum al-

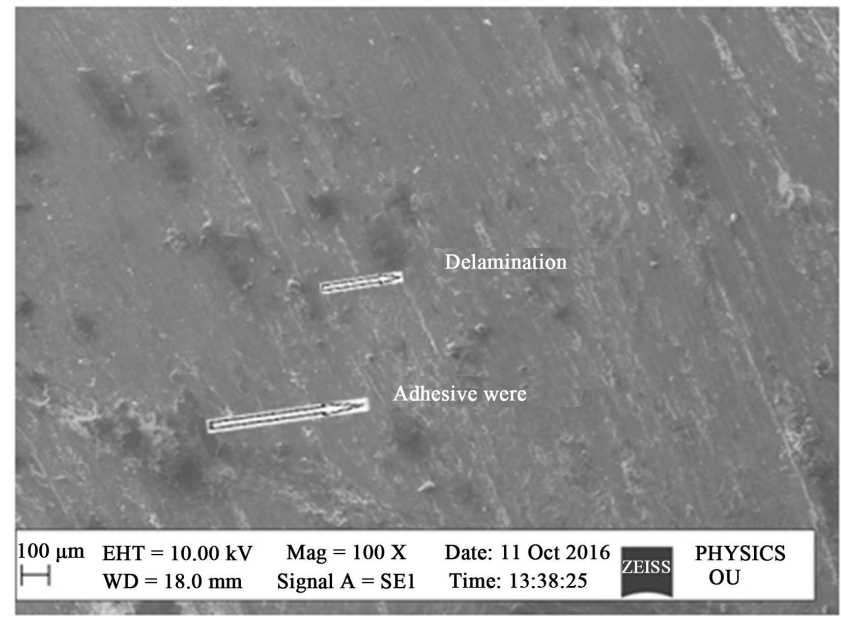

(a)

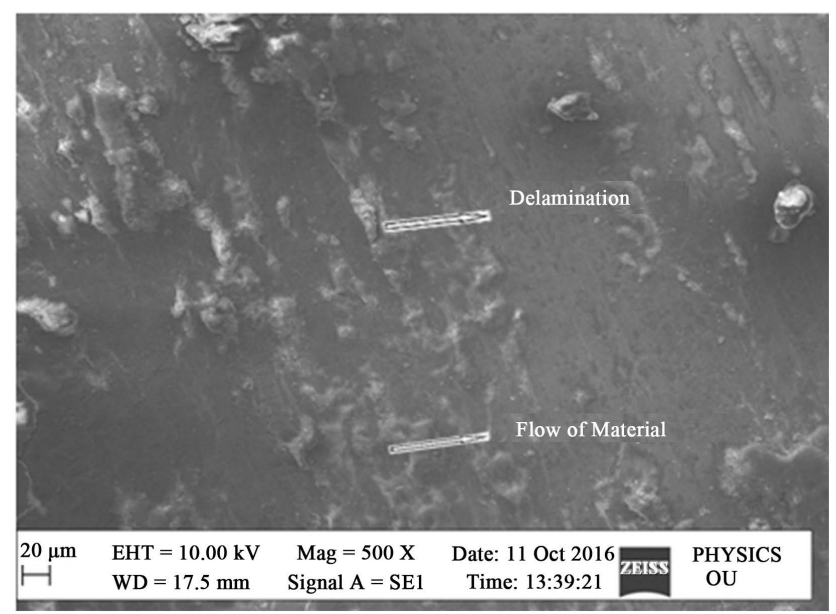

(c)

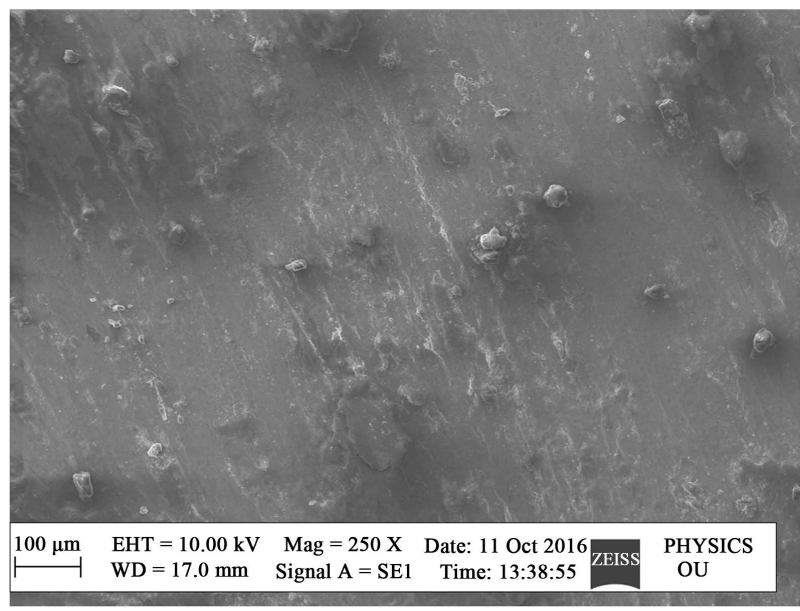

(b)

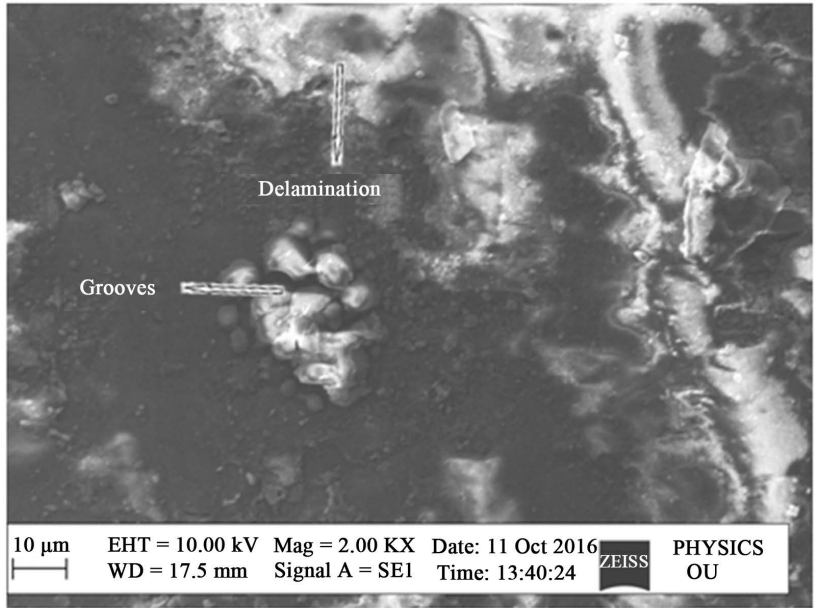

(d)

Figure 3. SEM images of worn surfaces of (a) base metal; (b) $4 \%$ composite; (c) $8 \%$ composite; (d) $12 \%$ composite. 
loy. It was found the plastic deformation on the worn surface can be significantly reduced by increasing $\mathrm{TiB}_{2}$ particles. The released debris particles from the surface of the composite avoids the direct metal to metal on the pin and disc surfaces which acts as a load bearing and acts as solid lubricant and there by reduces wear rate and the coefficient of friction. The similar observations were found with researchers [18] [22]. The abrasive wear mechanism dominated in composites. In other words, the reinforced particles of $\mathrm{TiB}_{2}$ pulled out the surface of composite and formed on the rotating disc which acts as barrier and converts into abrasive mode from adhesive wear. Further it was found that wear rate has decreased with increase of reinforcement which might be due to improved mechanical properties of composites.

The Table 3 shows the mass loss and corrosion rate for base metal and composites. It is observed that the mass loss and corrosion rate of composites were low as compared to the base metal. This indicates that composites will be suitable for sea environments and marine applications. The similar type of observations made by different researchers [23] [24]. The Figure 4 shows the SEM image of $8 \%$ composite and base metal. The corrosion rate i.e. more loss of material of the composites is predominantly due to formation of pits, cracks on the surfaces. The cracks are more in base metal than composites. The reinforcement

Table 3. Weight loss of material, corrosion rate of base metal and composites.

\begin{tabular}{|c|c|c|c|}
\hline Sample & $\begin{array}{l}\text { Weight loss } \\
\text { (grams) }\end{array}$ & $\begin{array}{c}\text { Corrosion rate } \\
\text { (mm/year) }\end{array}$ & $\begin{array}{c}\text { Corrosion rate } \\
\text { (miles/year) }\end{array}$ \\
\hline Base Metal & 0.006 & 0.004026 & 1.90 \\
\hline AA $6061-\mathrm{TiB}_{2} 0 \% \mathrm{MMC}$ & 0.005 & 0.00335 & 1.581 \\
\hline AA $6061-\mathrm{TiB}_{2} 4 \% \mathrm{MMC}$ & 0.004 & 0.00268 & 1.264 \\
\hline AA $6061-\mathrm{TiB}_{2} 8 \% \mathrm{MMC}$ & 0.002 & 0.01205 & 0.57 \\
\hline AA $6061-\mathrm{TiB}_{2} 12 \% \mathrm{MMC}$ & 0.005 & 0.00335 & 1.58 \\
\hline
\end{tabular}

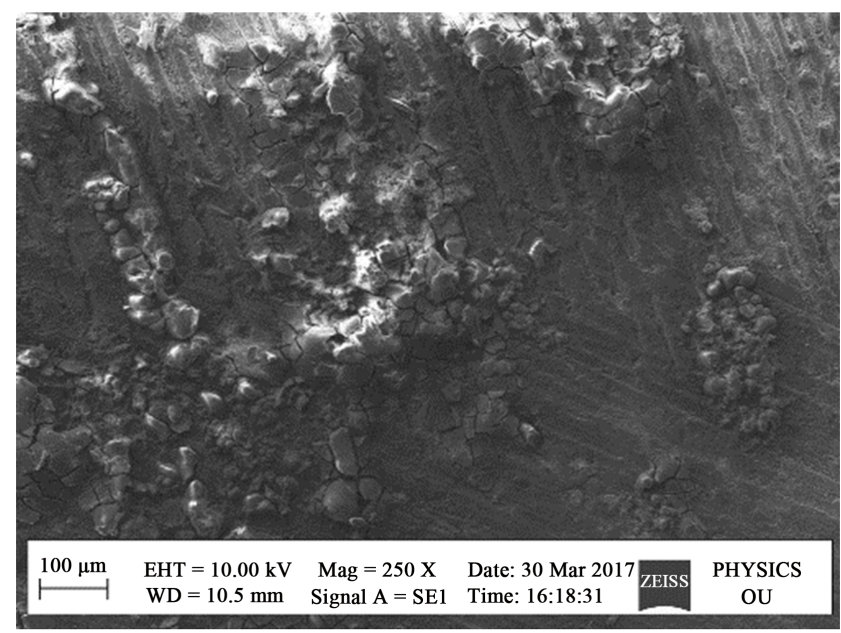

(a)

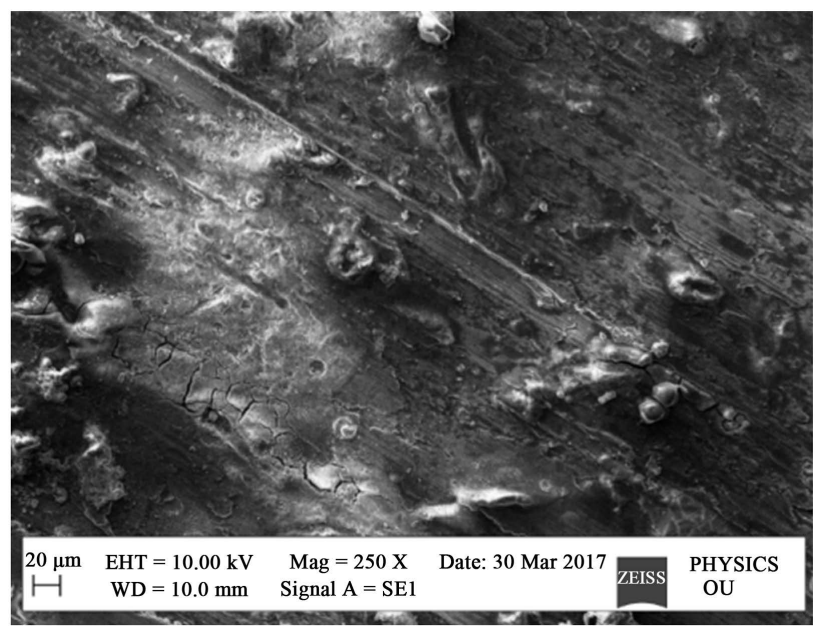

(b)

Figure 4. Corroded surface (a) base metal; (b) 8\% composite. 
being a ceramic in composites, remain inert and hard not effected by acidic medium during the test. The pitting corrosion was more predominant in composites.

\section{Conclusion}

The FSP is a successful method for production of aluminum composites. The mechanical properties were improved with increase of reinforcement particles. The wear rate was decreased with increase of composites. The lowest wear rate of $0.6282 \mathrm{~mm}^{3} / \mathrm{m}$ was obtained for $8 \%$ due to reinforcement particles which acts as third body whereas more wear rate for $12 \%$ composite due to less strength and hardness. The corrosion rate was decreased for $8 \%$ composite.

\section{References}

[1] Bakes, H., Benjamin, D. and Kirkpatrick, C.W. (1979) Metals handbook, vol. 2. OH: ASM. Metals Park, 2, 3-23.

[2] Salehi, M., Farnoush, H. and Mohandesi, J.A. (2014) Fabrication and Characterization of Functionally Graded Al-SiC Nano Composite by Using a Novel Multistep Friction Stir Processing. Materials and Design, 63, 419-426. https://doi.org/10.1016/j.matdes.2014.06.013

[3] Sharifi, E.M., Karimzadeh, F. and Enayati, M.H. (2011) Fabrication and Evaluation of Mechanical and Tribological Properties of Boron Carbide Reinforced Aluminum Matrix Nano Composites. Materials and Design, 32, 3263-3271. https://doi.org/10.1016/j.matdes.2011.02.033

[4] Baradeswaran, A. and Elaya Perumal, A. (2013) Influence of B4C on the Tribological and Mechanical Properties of Al 7075-B4C Composites. Composites B, 54, 146-152. https://doi.org/10.1016/j.compositesb.2013.05.012

[5] Alanemea, K.K., Akintunde, I.B., Olubambi, P.A. and Adewale, T.M. (2013) Fabrication Characteristics and Mechanical Behavior of Rice Husk Ash-Alumina Reinforced Al-Mg-Si Alloy Matrix Hybrid Composites. Journal of Material Research and Technology, 2, 60-67. https://doi.org/10.1016/j.jmrt.2013.03.012

[6] Kumar, A., Lal, S. and Kumar, S. (2013) Fabrication and Characterization of A359/Al2O3 Metal Matrix Composite Using Electromagnetic Stir Casting Method. Journal of Material Research Technology, 2, 250-254. https://doi.org/10.1016/j.jmrt.2013.03.015

[7] Yigezu, B.S., Mahapatra, M.M. and Jha, P.K. (2013) Influence of Reinforcement Type on Microstructure, Hardness, and Tensile Properties of an Aluminum Alloy Metal Matrix Composite. Journal of Minerals and Materials Characterization and Engineering, 1, 124-130. https://doi.org/10.4236/jmmce.2013.14022

[8] Kalkanli, A. and Yilmaz, S. (2008) Synthesis and Characterization of Aluminum Alloy 7075 Reinforced with Silicon Carbide Particulates. Materials and Design, 29, 775-780. https://doi.org/10.1016/j.matdes.2007.01.007

[9] Bacciarini, C. and Mathier, V. (2014) Aluminium AA6061 Matrix Composite Reinforced with Spherical Alumina Particles Produced by Infiltration: Perspective on Aerospace Applications. Journal of Metallurgy, Article ID 248542, 10.

[10] Jiang, L.T., Chen, G.Q., He, X.D., Zhao, M., Xiu, Z.Y., Fan, R.J. and Wu, G. (2009) Microstructure and Tensile Properties of TiB2p/6061 Al Composites. Transactions of Nonferrous Metals Society China, 19, 542. 
https://doi.org/10.1016/S1003-6326(10)60105-7

[11] Umasankar, V. (2014) Experimental Evaluation of the Influence of Processing Parameters on the Mechanical Properties of Sic Particle Reinforced AA6061 Aluminium Alloy Matrix Composite by Powder Processing. Journal of Alloys and Compounds, 582, 380-386.

[12] Thomas, M., Nicholas, E.D., Needham, J.C., Murch, M.G., Temple Smith, P. and Dawes, C.J. (1991) The Welding Institute, TWI, International Patent Application No. PCT/GB92/02203 and GB Patent Application No. 9125978.8.

[13] Thangarasu, A., Murugan, N., Dinaharan, I. and Vijay, S.J. (2014) Synthesis and Characterization of Titanium Carbide Particulate Reinforced AA6082 Aluminium Alloy Composites via Friction Stir Processing. Archives of Civil and Mechanical Engineering, ACME, Vol. 233, 11.

[14] Anvari, S.R., Karimzadeh, F. and Enayati, M.H. (2013) Wear Characteristics of Al-Cr-O Surface Nano-Composite Layer Fabricated on Al6061 Plate by Friction Stir Processing. Wear, 304, 44-151.

[15] Rajnesh, T. (2005) Synthesis and Tribological Characterization of in Situ Cast Al-TiC Composites. Wear, 259, 569-576.

[16] Gopalakrishnan, S. and Murugan, N. (2012) Production and Wear Characterisation of AA 6061 Matrix Titanium Carbide. Composites. Part B, 43, 302-308.

[17] Ashok Kumar, B.N. and Murugan, I.D. (2014) Dry Sliding Wear Behavior of Stir Cast AA6061-T6/AlNp Composite. Transactions of Nonferrous Metals Society of China, 24, 1-11.

[18] Dinaharan, I. and Murugan, N. (2012) Dry Sliding Wear Behavior of AA6061/ZrB2 in Situ Composite. Transactions of Non Ferrous Metals Society China, 22, 810-818.

[19] Haque, S., Ansari, A.H. and Bharti, P.K. (2014) Effect of Process Parameters on Wear Rate of $\mathrm{Al}$ 6061-Cu reinforced SiCp Metal Matrix Composites. Journal of Material Environmental Sciences, 5, 1485-1489.

[20] Mandal, A., Chakraborty, M. and Murthy, B.S. (2007) Effect of TiB2 Particles on Sliding Wear Behaviour of Al-4Cu Alloy. Journal of Wear, 262, 160-166.

[21] Essam, R.I., Makoto, T., Tishiya, S. and Kenji, I. (2010) Wear Characteristics of Surface-Hybrid-MMCs Layer Fabricated on Aluminum Plate by Friction Stir Processing. Wear, 268, 1111-1121.

[22] Aruri, D., Adepu, K., Adepu, K. and Bazavada, K. (2013) Wear and Mechanical Properties of 6061-T6 Aluminum Alloy Surface Hybrid Composites [(SiC + Gr) and $(\mathrm{SiC}+\mathrm{Al} 2 \mathrm{O} 3)]$ Fabricated by Friction Stir Processing. Journal of Materials Research and Technology, 2, 362-369.

[23] Zhu, J. and Hihara, L.H. (2010) Corrosion of Continuous Alumina-Fibre Reinforced $\mathrm{Al}$ 2wt. \% Cu-T6 Metal Matrix Composite in 3.15wt. \% NaCl Solution. Corrosion Science, 52, 406-415.

[24] Alaneme, K.K. and Bodunrin, M.O. (2011) Corrosion Behavior of Alumina Reinforced Aluminium (6063) Metal Matrix Composites. Journal of Minerals \& Materials Characterization \& Engineering, 10, 1153-1165.

https://doi.org/10.4236/jmmce.2011.1012088 